\title{
Alloy Phase Diagram International Commission (APDIC) 2012 Best Paper Award: Journal of Phase Equilibria and Diffusion
}

The Journal of Phase Equilibria and Diffusion (JPED) congratulates the winners of the 2012 APDIC Best Paper Award:

Victor T. Witusiewicz, Anatoliy A. Bondar, Ulrike Hecht, and Tamara Y. Velikanova for their paper "Phase Equilibria in Binary and Ternary Systems with Chemical and Magnetic Ordering," Journal of Phase Equilibria and Diffusion, 2011, 32(4), p 329-349. APDIC has presented the Best Paper Award since 1996. The award is given for the best single paper in a particular year on the critical assessment of alloy phase diagram data of metals and ceramics, including thermodynamic assessment, theoretical calculation, and experiment.

The award was conferred in a ceremony with three of the winners, who are scientists or guests with ACCESS at their home institution in Aachen, Germany, on September 10, 2012, by Rainer Schmid-Fetzer, Chair of the Best Paper Award Committee of APDIC.

Professor Schmid-Fetzer said, "This high quality paper published in JPED won a tough race against competitors preselected by members of the Award Committee as the top papers appearing in the year 2011." In addition to JPED, papers were reviewed from five other journals: Calphad, Intermetallics, Journal of Alloys and
Compounds, Metallurgical and Materials Transactions $A$ and $B$, and International Journal of Materials Research (formerly Zeitschrift für Metallkunde). The prize given by APDIC consists of $\$ 500$ and certificates citing the authors, the work and the journal "For the best published manuscript on alloy phase diagram data in the year 2011."

APDIC was established in 1986 as an organization to promote the assessment of phase diagrams. Currently, 16 organizations from 25 countries are members.

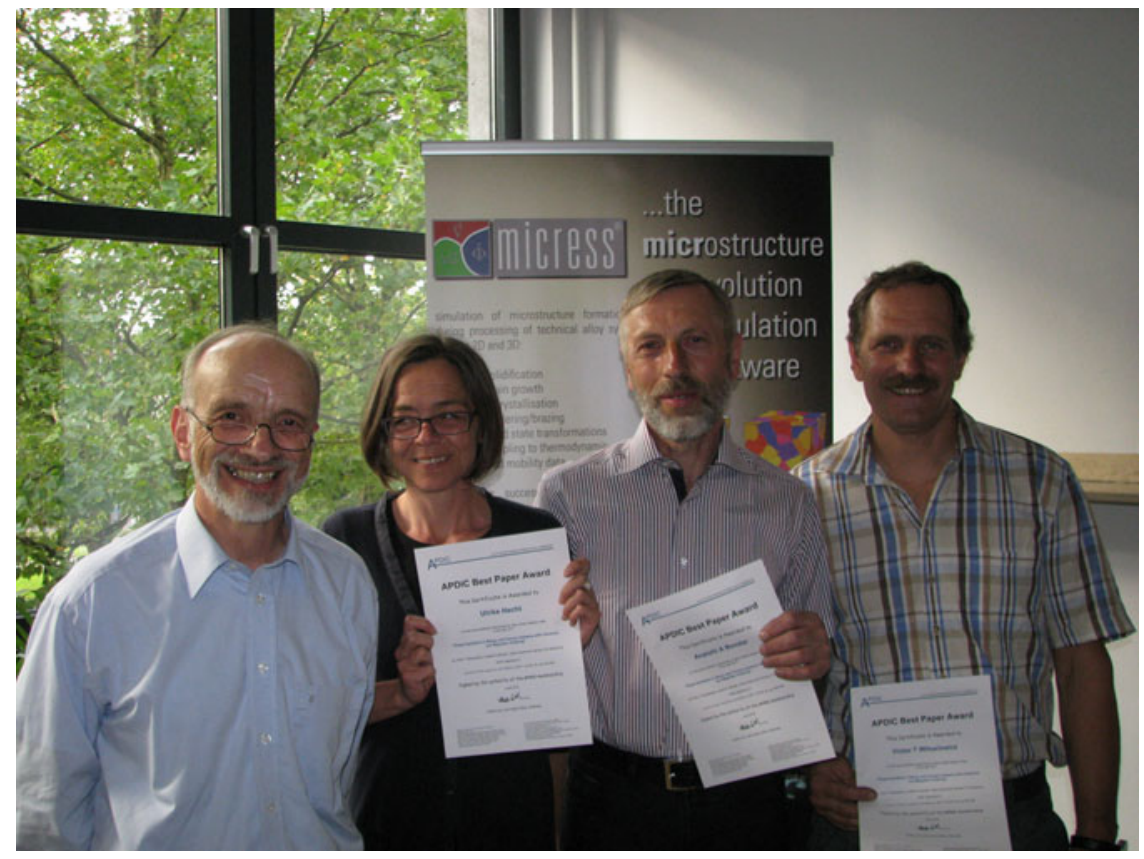

Three of the winners of the 2012 APDIC Best Paper Award, Victor Witusiewicz, Anatoliy Bondar, and Ulrike Hecht (from right to left) show their certificates, conferred by Rainer Schmid-Fetzer at the ceremony in Aachen, Germany, September 10, 2012 